\title{
Fluoride Induces Apoptosis in Mammalian Cells: In Vitro and In Vivo Studies
}

\author{
DANIEL ARAKI RIBEIRO ${ }^{1,2}$, CAROLINE MARGONATO CARDOSO ${ }^{2}$, \\ VERONICA QUISPE YUJRA ${ }^{2}$, MILENA DE BARROS VIANA ${ }^{1}$, ODAIR AGUIAR JR. ${ }^{1}$, \\ LUCIANA PELLEGRINI PISANI ${ }^{1}$ and CELINA TIZUKO FUJIYAMA OSHIMA ${ }^{2}$
}

Departments of ${ }^{1}$ Biosciences and ${ }^{2}$ Pathology, Federal University of Sao Paulo, UNIFESP, Sao Paulo, Brazil

\begin{abstract}
Apoptosis is genetically programmed cell death, an irreversible process of cell senescence with characteristic features different from other cellular mechanisms of death such as necrosis. In the last years, apoptosis has been extensively studied in the scientific literature, because it has been established that apoptosis plays a crucial role following the time course of chronic degenerative diseases, such as cancer. Thus, several researchers have strugged to detect what chemical agents are able to inter fere with the apoptotic process. Thus, the purpose of this literature review is to assess if fluoride induces apoptosis in mammalian cells using in vivo and in vitro test systems. Certain mammalian cell types such as oral cells, blood and brain were exetensively investigated; the results showed that fluoride is able to induce apoptosis in both intrinsinc and extrinsic pathways. Moreover, other cells types have been poorly investigated such as bone, kidney and reproductive cells with conflicting results so far. Therefore, this area needs further investigation for the safety of human populations exposed to fluoride in a chronic way, as for example in developing countries.
\end{abstract}

Fluoride is naturally present in the environment, being found in rocks, coal, and clay. Fluoride is an essential trace element encountered in small quantities in water, air, plants, and animals (1). It has long been recognized that fuoride in low concentrations is essential for teeth and

Correspondence to: Prof. Daniel A. Ribeiro, Department of This article is freely accessible online.

Biosciences, Federal University of Sao Paulo, UNIFESP, Av. Ana Costa, 95, Vila Mathias, Santos - SP, 11060-001, Brazil. Tel: +55 1332293756,e-mail: daribeiro@unifesp.br

Key Words: Fluoride, apoptosis, in vitro studies, in vivo studies, review. bone development being an effective agent for optimizing mineralized tissues (2).

For many years ago, the daily exposure of human organisms to fluoride depended on the intake of this ion with drinking water being closely associated with topographical regions. Since fluoride has been discovered as a chemical agent capable of inhibiting dental caries, it has been widely used in dentistry as a prophylactic agent (3). Herein, sodium fluoride $(\mathrm{NaF})$ has been incorporated to diverse applications, such as toothpastes, gels, drinks, salts, and others (4). As a consequence, the levels of fluoride exposure in human populations are increasing drastically, particularly in developing countries, where the control of exposure to the ion is not properly regulated by local government agencies. In fact, many side health effects have been attributed to excessive fluoride intake (5). This pathological condition is defined as fluorosis, which is characterized as a chronic long-term exposure to high levels of fluoride, clinically manifested by skeletal fragility and subsequent damage to internal organs, including kidneys, liver, and brain (6).

Apoptosis is genetically programmed cell death, an irreversible process of cell senescence with characteristic features (cell shrinkage, chromatin condensation, DNA fragmentation, apoptotic bodies) different from other cellular mechanisms of death such as necrosis (7). Two signaling pathways characterize the event: intrinsic or mitochondrial pathway mediated mainly by proteins belonging to the cl-2 family and the extrinsic pathway based on Fas type death receptors (7). Independent of the pathway involved in the process, apoptosis triggers the activation of caspases.

Nowadays, apoptosis has been extensively studied in the scientific literature, because it has been established that apoptosis plays a crucial role following the time course of chronic degenerative diseases, such as cancer (8). Thus, several researchers have struggled to clarify what chemical agents are able to inter fere with the apoptotic process. Some studies have demonstrated that excess fluoride can cause 
DNA damage, and change cell-cycle regulatory proteins that in turn induce apoptosis (9). However, the underlying mechanisms of apoptosis induced by fluoride are still unclear; especially to identify the signaling pathways that are closely involved to this process.

Thus, the purpose of this literature review is to assess whether fluoride induces apoptosis in mammalian cells using in vivo and in vitro test systems. Certainly, our critical analysis will provide new knowledge regarding the issue for future perspectives, specifically because there is limited information concerning the mechanism of fluoride-induced cell death so far.

\section{In Vitro Studies}

As expected, most in vitro studies have investigated the effects of fluoride on mineralized cells such as odontoblasts, ameloblasts and bone cells. Certainly, this is because fluoride interacts directly with mineralized tissues. Herein, it has been purposed several signaling pathways regarding apoptosis process. Such information was very important for better understanding the cytotoxicity induced by fluoride. However, such mechanisms needed to be confirmed by in vivo studies since in vitro assays do not consider the complex homeostatic condition that occurs in vivo, especially when investigating systemic exposure to chemical agents. The results are shown below.

Oral cells. First molar germs from 1-day-old Balb/c mice exposed to increasing concentrations of fluoride $(0 \mathrm{mM}, 1 \mathrm{mM}$ and $5 \mathrm{mM}$ ) revelated disorganization in ameloblast and odontoblast-papilla zones (10). Caspase 8, caspase 3, Bax, Bid increased expression and subsequent more TUNEL positive cells in fluoride groups were noticed (10). Eluates derived from glass ionomer cements releasing fluoride continously also showed the presence of apoptotic process as depicted by high annexin $\mathrm{V}$ expression in human dental pulp cells (11).

When odontoblast cells were exposed to $\mathrm{NaF}$ at $3 \mathrm{mM}$, cells detached from their support and did not proliferate (12). Odontoblast like cells incubated with $\mathrm{NaF}$ at $5 \mathrm{mM}$ exhibited caspase- 3 activation, cleavage of poly(ADP-ribose) polymerase, DNA fragmentation, and the presence of cytoplasmic nucleosomes as well as ultrastructural alterations $(13,14)$. This resulted in the translocation of Bax to the mitochondria and the release of cytochrome $c$ from the mitochondrial inter-membrane space into the cytosol, indicating that fluoride-mediated apoptosis ismitochondria-dependent (14). NaF exposure induced a biphasic phosphorylation of extracellular signal-regulated protein kinase (ERK) (13). Thus, exposure to NaF induces apoptosis in odontoblast-like cells, mainly through extrinsic apoptotic pathways depending on JNK and, less significantly, ERK pathways $(13,14)$. However, necrosis was detected to this concentration of fluoride showing that fluoride leads to an insult of high magnitude to the cellular apparatus (12).
Ameloblasts also showed high sensitivity to fluoride with respect to cytotoxicity, especifically apoptosis. Flow cytometry showed that both $10 \mu \mathrm{M}$ and $20 \mu \mathrm{M}$ NaF significantly increased the apoptotic index of ameloblast-lineage cells (15). Morphologically, high fluoride incubation damaged the ameloblast ultrastructure manifesting a series of intracellular stress responding cell organelle destruction, and a marked increase in the expression of apoptotic genes (16-18). Ameloblasts were growth-inhibited by as little as 1.9-3.8 ppm fluoride, whereas higher doses of this one induced endoplasmic reticulum stress and caspase-mediated DNA fragmentation increased intracellular $\mathrm{Ca}^{2+}$ in vitro in a dose related fashion (19-21). The endoplasmic reticulum stress has been closely related to X-box binding protein 1 (XBP-1) (21). On the other hand, some authors have revealed that excessive fluoride inhibited cell proliferation of ameloblasts (22). Others have yet reported that fluoride had a dual effect on cell proliferation, with enhanced proliferation at $16 \mu \mathrm{M}$, and reduced proliferation at greater than $1 \mathrm{mM} \mathrm{F} \mathrm{(23).}$

At protein and molecular levels, fluoride induced ameloblast apoptosis via activation of the FasL/Fas signaling pathway (Wang et al. 2016). Fluoride promoted cytochrome$c$ release, up-regulation of $\mathrm{UCP} 2$, attenuation of ATP synthesis, and H2AX phosphorylation $(\gamma \mathrm{H} 2 \mathrm{AX})(18)$. High amounts of fluoride induced more apoptosis/dead cells and reduced the expression of Bcl-2 decreased expression along with up-regulated expression of CD68 $(15,22)$. Furthermore, a decreased expression and increased phosphorylation of Foxo1 in NaF-treated ameloblast cells has been shown (24). Recently, it has been demonstrated that $\mathrm{NaF}$ prevented apoptosis of ameloblast cells, by decreasing protein levels of cytoplasmic cytochrome $c$, cleaved caspase-9, and cleaved caspase- 3 and caspase 8 while increasing the Bcl-2/Bax ratio and JNK expression level $(21,24)$. Fluoride treatment of ameloblast-derived cells significantly increased SIRT1 expression and induced SIRT1 phosphorylation resulting in the augmentation of SIRT1 deacetylase activity (17). Such findings demonstrated that fluoride is able to inhibit apoptosis via p53 acetylation pathway. Recently, western blot revealed that the protein expression of p-ERK and p-JNK were decreased, while the expression of p38 was increased (21). Taken as a whole, it seems that fluoride has a dual role on apoptosis in ameloblasts.

Expression of beclin1, which is required for autophagosome formation, decreases the expression of mTOR increased at $1.2 \mathrm{mmol} / 1 \mathrm{NaF}$ (25). Fluoride promoted cytochrome-c release, up-regulation of $\mathrm{UCP} 2$, attenuation of ATP synthesis, and $\mathrm{H} 2 \mathrm{AX}$ phosphorylation $(\gamma \mathrm{H} 2 \mathrm{AX})$ as far as DNA damage and cell death (18). Additionally, immunohistochemical analysis was performed on paraffinembedded rat incisor sections to identify the expression of Beclin1 and mTOR proteins in vitro. Fluoride induced highly significant differences between non-exposed groups (25). 
These findings suggest that NaF-induced apoptosis of ameloblast cells via inhibiting the mitochondrial pathway and activating caspases as a putative mechanism of dental fluorosis. Therefore, these results suggest that fluoride causes mitochondrial damage, that may lead to impairment of ameloblast function.

$\mathrm{NaF}$ reduced the cell viability of human gingival fibroblasts in a dose- and time-dependent manner (26). NaF increased TUNEL-positive cells and induced apoptosis by means of concomitant chromatin condensation and subsequent DNA fragmentation (26). In addition, $\mathrm{NaF}$ increased the release of cytochrome $c$ from the mitochondria into the cytosol, as well as enhanced the caspase- $9,-8$ and -3 activities, the cleavage of poly (ADP-ribose) polymerase (PARP), and up-regulated the voltage-dependent anion channel (VDAC) 1 (26). Furthermore, NaF up-regulated the Fas-ligand (Fas-L), and Bcl-2 was down-regulated. Expression of Bax was unaffected in the NaF-treated human gingival fibroblasts (26). These results suggest that $\mathrm{NaF}$ induces apoptosis in human gingival fibroblasts through both the mitochondria-mediated pathways regulated by the Bcl-2 family and death receptor-mediated pathway (26).

When rat oral epithelial cells were exposed to $\mathrm{NaF}$, a relatively high concentration of $\mathrm{NaF}(2 \mathrm{mM})$ induced cell death concomitant with decreases in mitochondrial membrane potential, chromatin condensation and caspase-3 activation (27). Such findings suggest that $\mathrm{NaF}$ did not activate caspase 3 in oral mucosa cells.

The gene networks Up-I and Up-II included many upregulated genes that were mainly associated with the biological function of induction or prevention of cell death, such as Atf3, Ddit3 and Fos (for Up-I) and Atf4 and Hspa5 (for Up-II). Interestingly, knockdown of Ddit3 and Hspa5 significantly increased and decreased the number of viable cells, respectively (27). Moreover, several endoplasmic reticulum stress-related genes including, Ddit3, Atf4 and Hapa5, were observed in these gene networks (27). These findings will provide further insight into the molecular mechanisms of $\mathrm{NaF}$ induced cell death accompanying endoplasmic reticulum stress in oral epithelial cells (27). When human squamous cell carcinoma cells were exposed to $\mathrm{NaF}$, activated caspase 3 and subsequent DNA fragmentation was observed $(28,29)$. Also, $\mathrm{NaF}$ interferes with Bad-Bcl-2 complex by means of carbonic anhydrase II detachment from Bad protein, contributing, therefore, to the apoptosis process (30).

Bone cells. To date, some mechanisms have been purposed with regard to apoptosis induced by fluoride in bone cells. For example, osteoblasts were exposed to different concentrations of $\mathrm{NaF}(10(-6)-5 \times 10(-4) \mathrm{M})$; the results revealed that $\mathrm{NaF}$ inhibited proliferation and arrested cell cycle at $\mathrm{S}$ phase as far as induced apoptosis (31-38). This was detected by activation of caspase 3 and 9 in osteoblast cells (32). Nevertheless, others have failed to detect caspase 3 activation after fluoride exposure to bone cells (39).

MTT assay showed that NaF at concentrations of $10^{-8}$ to $10^{-5} \mathrm{M}$ promoted cell proliferation, whereas at $10^{-4}$ to $10^{-3} \mathrm{M}$ it suppressed cell proliferation and induced apoptosis in caprine osteoblasts $(33,36)$. Such findings lead to the putative dual role of fluoride on cell cycle regulatory proteins, which is dosedependent. Apoptosis induced by fluoride was due to alterations in the expression of both pro-apoptotic Bax and anti-apoptotic Bcl-2 (33). Particularly, there was a decrease in the Bcl-2/Bax ratio, which was found at both the mRNA and protein levels (33). Others have revealed that fluoride induced apoptosis through the MAPK/ERK signaling pathway (37).

$\mathrm{NaF}$ increased oxidative stress and decreased protein expression of IGF-I contributing to proliferation and apoptosis (31). Such findings suggest that the administration of $\mathrm{NaF}$ affects the rat osteoblast survival (33). Alkaline phosphatase (ALP) activity and mineralization ability increased in cells treated at $10^{-8}$ to $10^{-5} \mathrm{M}$ with sodium, but decreased at $5.0 \times 10^{-4}$ to $10^{-3} \mathrm{M}$ dosage in caprine osteoblasts (36). Other authors have demonstrated no increase of alkaline phosphatase activity in bone cells exposed to fluoride (39). Conversely, calvaria cells were cultured for 28 days in the presence of several doses of $\mathrm{NaF}$ $(0,5,10,25,50$, and $75 \mu \mathrm{M})$, the results showed no effects on alkaline phosphatase activity but decreased mineralized nodule formation (40). These negative effects include decreased COLIAI mRNA, down-regulating the synthesis of COL1 protein. The results suggest that COL1 protein degradation following fluoride toxicity is due to a depletion of COL1A1 mRNA and not COL1A2 (33).

Osteoblasts also showed a reduction in the mineralization pattern only after $50 \mu \mathrm{M}$ of $\mathrm{NaF}$ with a slight increase of type-I collagen and down-regulation of MMP-2 activity during the mineralization period (40). In conclusion, fluoride affects the production and degradation of the extracellular matrix during early onset and probably during the mineralization period.

The PCR chip detection found 13 up-regulating genes and 15 down-regulating genes, among which the expression of Bim, caspase 9, caspase 14, B-cell lymphoma-2 (Bc12) and Bax increased with the doses of sodium fluoride, while the expression of caspase 3 was down-regulated in $5 \mathrm{mg} / \mathrm{l}$ sodium fluoride but up-regulated at the concentration of more than 10 $\mathrm{mg} / \mathrm{L}$ sodium fluoride (41). Caspase 7 expression showed no obvious difference between the different concentration groups (41). However, caspase 10 decreased with the increasing doses of sodium fluoride (41). The underlying mechanisms of apoptosis induced by fluoride may be through the mitochondrial pathway (including endoplasmic reticulum stress pathway) and death receptor pathway (41). After scrutinizing the genome, it plausible to believe that fluoride induces apoptosis in osteoblast cells (38). 
Blood cells. Human myeloma peripheral blood cells were cultured with increasing doses of fluoride $(10,20,40,80$, $160,320 \mu \mathrm{M})$. After $48 \mathrm{~h}$ exposure, fluoride increased cells viability at relatively low levels (10-160 $\mu \mathrm{M})$; however, when the concentration reached $320 \mu \mathrm{M}$, the cell proliferation was significantly inhibited (42) and subsequent cell hemolysis occurence within $24 \mathrm{~h}$ in the presence of 0.5 $16 \mathrm{mM}$ of $\mathrm{NaF}$ (43). Morphologically, this change was characterized by shrunken echinocytes after $1 \mathrm{~h}$ and swollen spherocytes within $24 \mathrm{~h}$ (43). The development of NaFinduced erythrocyte death was accompanied by progressive positivity of annexin $\mathrm{V}$-staining in response to $16 \mathrm{mM} \mathrm{NaF}$ within $24 \mathrm{~h}$ with a small cell population exhibiting necrotic features (43). The results suggest that overexposure to fluoride (160-320 $\mu \mathrm{M})$ can induce cytotoxicity and regulate relevant genes expression $(42,44)$. Taken together, all findings confirm earlier reports on mechanisms involved in $\mathrm{NaF}$-induced apoptosis in blood cells (45).

At the molecular level, mRNA expression of genes, including ANKRD1, CRSP6, KLF2, SBNO2, ZNF649, FANCM, PDGFA, RNF152, CDK10, and CETN2 changed in a concentration-dependent manner and increased with fluoride exposure concentration in blood cells (42). Treatment of rat erythrocytes with $5 \mathrm{mM} \mathrm{NaF}$ for 1-24 h caused progressive accumulation of cytosolic $\mathrm{C}^{\mathrm{a} 2+}$ in the outer membrane surface (43). Incubation of erythrocytes with 0.1-10 $\mathrm{mM} \mathrm{NaF}$ for $1 \mathrm{~h}$ produced a dose-dependent PKC $\alpha$ translocation from cytosol to membranes with appearance of active PKM fragment. NaF exposure for $14 \mathrm{~h}$ led to complete loss of cytosolic PKC $\alpha$ and proteolysis of membrane PKC $\alpha$ (43). Besides, NaF weakly stimulated membrane $\mathrm{PKC} \zeta$, although its subcellular distribution was not altered. Thus, transient PKC $\alpha$ activation/translocation positively contributes to $\mathrm{NaF}$-induced apoptosis in vitro (43).

Splenic lymphocytes from mice were exposed to $\mathrm{NaF}(0$, $100,200$, and $400 \mu \mathrm{mol} / \mathrm{l})$ in vitro for 24 and $48 \mathrm{~h}(46,47)$. $\mathrm{NaF}$ induced lymphocyte apoptosis, which was promoted by decreasing mitochondria transmembrane potential, upregulation of Bax, Bak, Fas, FasL, caspase 9, caspase 8, caspase 7 , caspase 6 and caspase 3 protein expression and down-regulation of $\mathrm{Bcl}-2$ and $\mathrm{Bcl}-\mathrm{xL}$ protein expression $(46,47)$. The above-mentioned data suggested that NaFinduced apoptosis in splenic lymphocytes could be mediated by mitochondrial intrinsic pathway and death receptor pathways.

Fluoride also induced apoptosis in human leucemia cells in a dose- and time-dependent manner (48). Many authors have proven that fluoride led to the activation of caspase- 3 and caspase-9 (49-52) at higher concentrations (100-250 ppm), reduced cell viability, and decreased DNA and protein biosynthesis capability in cultured HL-60 cells. Morphologically, NaF promoted internucleosomal DNA fragmentation, and increased the proportion of hypodiploid cells (48). After exposure to $\mathrm{NaF}$, there was an increase in MDA and 4-HNE and a loss of mitochondrial membrane potential (deltaPsi(m)) was also observed in NaF-treated cells (50). There was a significant increase in cytosolic cytochrome $c$, which is released from the mitochondria (50). This leads to down-regulation of $\mathrm{Bcl}-2$ protein in $\mathrm{NaF}$ treated cells in human leukemia cells $(48,50)$. However, others have assumed that $\mathrm{NaF}$ enhanced the expression of Bad protein, but not that of Bcl-2 and Bax proteins, and reduced HIF-1alpha mRNA expression (51).

Brain cells. The levels of apoptosis and c-Jun N-terminal kinases (JNK) in brain cells exposed to different concentrations of sodium fluoride (NaF) were detected (53). At a concentration of $50 \mathrm{ppm}$ of fluoride, the increased apoptotic death rate was evidenced (53).

Fluoride induced apoptosis in hippocampal cell line (54). Primary rat hippocampal neurons were incubated with 20 , 40 , and $80 \mathrm{mg} / \mathrm{l}$ sodium fluoride for $24 \mathrm{~h}$ in vitro (55). The results showed that the cell survival rate in the $80 \mathrm{mg} / 1$ fluoride-treated group was significantly lower (55). As expected, the significant differences of intracellular $\mathrm{Ca}^{2+}$ concentration and apoptotic peaks were found in 5.0-40.0 $\mathrm{mg} \mathrm{NaF/L} \mathrm{groups} \mathrm{in} \mathrm{rat} \mathrm{hippocampal} \mathrm{neurons} \mathrm{(56).} \mathrm{With}$ respect to NCAM mRNA expression levels, a significant dose-dependent decrease was observed with 40 and $80 \mathrm{mg} / 1$ fluoride in hippocampal cells (55). In addition, protein expression levels of NCAM-180 in 40 and $80 \mathrm{mg} / 1$ fluoride-treated groups, NCAM-140 in all fluoride-treated groups, and NCAM-120 in the $80 \mathrm{mg} / \mathrm{l}$ fluoride-treated group were significantly decreased (55). Therefore, it is a concensus that fluoride could cause apoptosis, and decreased mRNA and protein expression levels of NCAM in rat hippocampal neurons. Such findings clarify part of the biological mechanisms of neurotoxicity induced by fluoride.

When brain tumor cells were exposed to fluoride, similar findings were found. For example, human neuroblastoma cells were incubated with $0,20,40$, and $80 \mathrm{mg} / \mathrm{L}$ sodium fluoride $(\mathrm{NaF})$ for $24 \mathrm{~h}$ in vitro. The data show that cell viability in the 40 and $80 \mathrm{mg} / 1$ fluoride groups were significantly lower than that of the control group (57). The percentages of apoptosis in the 40 and $80 \mathrm{mg} / 1$ fluoride groups were markedly higher in a dose-dependent manner. The activity of caspase- 3 and mRNA expression levels for Fas, Fas-L, and caspases (-3 and -8$)$ in the 40 and $80 \mathrm{mg} / \mathrm{l}$ fluoride groups were significantly higher as well (57). The results indicate that fluoride exposure could induce apoptosis in brain tumor cells, and the Fas/Fas-L signaling pathway may play an important role in the process (57).

Reproductive cells. When Sertoli cells were exposed do fluoride in vitro, endoplasmic reticulum stress, decreased cell viability and apoptosis was detected at varying doses (58). 
The endoplasmic stress as evidenced by up-regulated glucose-regulated protein $78 \mathrm{kDa}$ (GRP78), PKR-like ER kinase (PERK), phosphorylation of eukaryotic translation initiation factor $2 \alpha$ (p-eIF2 $\alpha$ ) and CCAAT/enhancer-binding protein-homologous protein $(\mathrm{CHOP})$, without affecting total eukaryotic translation initiation factor $2 \alpha$ (eIF2 $\alpha$ ) (59). In addition, $\mathrm{NaF}$ facilitated the accumulation of ROS and increased nuclear translocation of nuclear factor erythroid 2related factor 2 (Nrf2) in Sertoli cells $(58,59)$. The levels of FasL protein and mRNA decreased with the increase of fluoride concentration in mouse sertoli cells (60). The caspase 8 and caspase 3 mRNA levels were also decreased in fluoride groups in a dose-dependent manner (60). These findings indicated that fluoride triggered apoptosis by the Fas/FasL system, but it was not able to activate caspase 3 .

The chemical effects of $\mathrm{NaF}$ on Leydig cells were also demonstrated since high dosage of $\mathrm{NaF}$ inhibited cell proliferation by stress-induced apoptosis (61). The intrinsic signalling apoptotic pathway was activated by fluoride exposure including caspase-3/caspase-9, B-cell lymphoma 2 (Bcl-2), and Bax (61).

Liver cells. Few studies have demonstrated apoptosis induced by fluoride in liver cels. Fluoride caused apoptosis and increased cell numbers in $\mathrm{S}$ phase of cell cycle in human embryo hepatocytes exposed to sodium fluoride at different doses (40 microg/mL, $80 \mathrm{microg} / \mathrm{mL}$, and $160 \mathrm{microg} / \mathrm{mL}$ ) for $24 \mathrm{~h}$ (62). There is a significant positive correlation between fluoride concentration and these pathological changes (62). Other findings showed that the percentage of apoptosis and c-Fos mRNA and protein expression levels in 40 and $80 \mathrm{mg} / \mathrm{l} \mathrm{NaF-treated} \mathrm{groups} \mathrm{were} \mathrm{higher} \mathrm{in} \mathrm{liver} \mathrm{cells}$ (63). c-Fos methylation levels were decreased in 20, 40, and $80 \mathrm{mg} / \mathrm{l} \mathrm{NaF-treated} \mathrm{groups} \mathrm{against} \mathrm{the} \mathrm{control} \mathrm{group} \mathrm{(63).}$ Further, Dnmt1 mRNA expression level was significantly decreased in the $80 \mathrm{mg} / \mathrm{l} \mathrm{NaF}$-treated groups; Dnmt3a and Dnmt3b mRNA expression levels were significantly decreased in 40 and $80 \mathrm{mg} / \mathrm{l} \mathrm{NaF-treated} \mathrm{groups} \mathrm{(63).} \mathrm{These}$ results suggest that $\mathrm{NaF}$ could induce apoptosis and upregulate mRNA and protein expression level of c-Fos as well as decrease mRNA expression levels of Dnmt1, Dnmt3a, and Dnmt3b in L-02 cells. The decrease in c-Fos methylation levels might be involved in the early phase of apoptosis induced by $\mathrm{NaF}$ liver cells (63).

Incubation of hepatocytes with $\mathrm{NaF}$ increased apoptosis of HepG2 cells (64). Proliferation slightly increased and then decreased with a high fluoride treatment (64).

Lung. Lung epithelial cells were exposed to sodium fluoride (NaF-5 mM) alone for $24 \mathrm{~h}$ induced apoptosis as well as inhibited cell proliferation $(65,66)$. Furthermore, fluoride activated changes in mitochondrial membrane potential, permeability transition pore opening, cytochrome- $c$ release, Bax/Bcl-2 ratio, caspase-3 and PARP-1 expressions (67).

\section{In Vivo Studies}

Oral cells. In vivo studies failed to investigate the effects induced by fluoride regarding the apoptotic process. Nevertheless, some pathobiological mechanisms have been purposed so far. Rats exposed to fluoride at $150 \mathrm{mg} / \mathrm{L}$ contributed to cell cycle disruption of oral cells as depicted by a lower cell number at $\mathrm{G}_{0} / \mathrm{G}_{1}$ as well as mitotic cells (68). In humans, exfoliate cytology in oral mucosa cells of individuals with diagnosed fluorosis pointed out apoptosis process as demonstrated by the increased nuclear size and decreased cell size (69). Toppical application of $1.23 \%$ acidulated phosphate fluoride to oral mucosa of rabbits after 1. 5 and 8 days of continuous exposure revealed genetic damage and morphological alterations indicative of apoptosis by transmission electron microscopy as depicted by loss of cell-to-cell contact, nuclear chromatin condensation and apoptotic bodies (70). At the molecular level, rats treated with fluoride at $10 \mathrm{mg} / \mathrm{kg}$ for 5 weeks showed that caspase9 and caspase-3, and the gene expressions of Bax were significantly increased (71).

In enamel organs from rats or mice treated with 50, 100, or 125 ppm fluoride for 6 weeks, cytochrome-c release was increased (18).

It has been widely documented in vitro that ameloblasts are very sensitive to the toxic effects of high dose fluoride in drinking water (19). However, some results are conflicting so far. Activated Ire1 initiates an endoplasmic reticulum stress response pathway, and mouse ameloblasts were shown to express activated Ire1 (19). Ire1 levels were induced by fluoride treatment, indicating that endoplasmic reticulum stress may play a role in dental fluorosis (19). It is assumed that low dose fluoride, such as that present in fluoridated drinking water, did not induce endoplasmic reticulum stress (19).

Bone. Surprisingly, only one study has been dedicated to fluoride cytotoxicity induced by apoptosis in bone cells so far. Wistar rats exposed to increasing concentration of fluoride $(50,100$, and $150 \mathrm{mg} / \mathrm{l})$ for 8 weeks showed that expression of GRP78, XBP1, caspase-12, and CHOP were increased in a dose-dependent manner (72). Fluoride-induced apoptosis in osteoblasts was also dose-dependent. High concentrations of fluoride induced endoplasmic reticulum stress and osteoblast apoptosis in vivo (72). Caspase-12 and CHOP activation was associated with osteoblast apoptosis (72). To understand the real biological effects that are involved with the cytotoxicity induced by fluoride in bone cells remains to be elucidated.

Blood. Since peripheral blood reflects a systemic exposure to several chemical compounds, there are many studies investigating the effects of fluoride in these cells Children chronically exposed to fluoride at $5.3 \mathrm{mg} / 1$ in drinking water 
and in food cooked with the same water showed a lower percentage of CD25- and CD40-positive cells (73). The same findings were observed in others (74).

Broilers exposed to high-fluoride diets containing 0, 400, 800 , and $1,200 \mathrm{mg} / \mathrm{kg}$ fluorine showed that apoptotic lymphocytes were significantly increased with high-fluoride (75). Meanwhile, immunohistochemical tests showed that the Bcl-2 protein expression decreased, Bax and caspase-3 protein expression increased in lymphocytes of the highfluoride groups (75).

In rats exposed to increasing concentrations of fluoride (0$500 \mathrm{ppm}), \mathrm{p} 53, \mathrm{Bcl}-2$, and caspase-3 up-regulation was noticed in leukocytes (76). These results indicate that $\mathrm{NaF}$ intoxication can be an apoptosis inducer in rat leukocytes treated with the compound for eight weeks (76). However, others have mentioned that chronic exposure to fluoride at high concentrations (up to $100 \mathrm{ppm}$ ) did not produce any sign of apoptosis (77). Further studies are necessary to better understand what pathways closely to apoptosis are activated after fluoride exposure, because it is not possible to predict if fluoride is closely involved with the apoptosis process.

Liver. Rat hepatocytes exposed to fluoride revealed the presence of apoptosis when exposed to $150 \mathrm{mg} / \mathrm{L}$ for 4 weeks (68). Fluoride-induced morphological changes and significantly increased apoptosis and DNA damage in rats exposed to fluoride, by administering varying concentrations of fluoride $(0,50,100,200 \mathrm{mg} / \mathrm{l})$ for 120 days (78). This was confirmed by high expression of caspase-3, caspase- 9 protein expression with increasing $\mathrm{NaF}$ concentration in rat liver (78). The same results were confirmed in pigs exposed to high doses of fluoride (79).

Furthermore, cell cycle disruption as result of a lower number of liver cells undergoing cell divsion was noticed (68). An earlier study conducted by Campos-Pereira et al. (80) have affirmed that fluoride is not able to induce apoptosis in rat hepatic cells since no remarkable differences were noticed with a TUNEL assay. Nevertheless, morphological changes indicative of cytotoxicity such as empty nuclear spaces, cytoplasm degeneration, nuclear pyknosis, karyorrhexis and karyorrhexis followed by karyolysis were detected (80).

Fluoride induced up-regulation of some key genes closely related to oxidative damage, apoptosis, and mitochondrial stress (81). The expression of PI3K and Akt1 mRNA and proteins was significantly increased in fluorosed rat hepatocytes (81). The apoptosis and intracellular calcium concentration were also increased (81). The protein levels of Fas as well as FasL in NaF were significantly increased compared with those in the control group (82). Therefore, such published data have purposed several signaling pathways invoved to the pathogenesis of liver injury caused by fluorosis.
Spleen. Spleen of mice exposed to fluoride increased lymphocytes apoptosis, which was consistent with NaFcaused endoplasmic reticulum stress (46). Broilers exposed to high doses of fluoride presented endoplasmic reticulum stress in spleen cells that in turn leads to apoptosis as well (83). This was due to up-regulation of glucose-regulated protein 78 (BiP) and glucose-regulated protein 94 (GRP94), and by activating unfolded protein response (UPR) (46). Moreover, high expression of caspase 12 followed by, growth arrest, DNA damage and phosphorylation of JUN Nterminal kinase (p-JNK) were detected (46). Increased apoptosis ratio following caspase- 9 and caspase- 3 upregulation in the spleen of rats exposed to an excessive amount of fluoride was noticed (84).

Rats exposed to excessive fluoride had lower levels of IL$1 \beta$, IL-2, IL-6, TNF- $\alpha$, and IFN- $\gamma$ in the spleen (84). Light and transmisison electron microscopy revealed the irregularly arranged lymphocytes, few lymph nodules and the apoptotic characteristics of lymphocytes (84).

Reproductive system. $\mathrm{NaF}$ exposure induced an enhanced testicular apoptosis, as manifested by caspase- 3 activation, chromatin condensation and subsequent DNA fragmentation in rats (85). Further studies revealed that fluoride exposure elicited significant elevations in the levels of cell surface death receptor Fas with a parallel increase in cytoplasmic cytochrome $c$, indicating the involvement of both extrinsic and intrinsic apoptotic pathways (85). Overall, it seems that extrinsic and intrinsic signaling apoptotic pathways are closely actived by fluoride exposure.

Testis of male offspring were studied at 8 weeks of age exposed to fluoride during gestation. The results demonstrated that fluoride treatment enhanced germ cell apoptosis (86). In addition, fluoride elevated mRNA and protein levels of glucose-regulated protein 78 (GRP78), inositol requiring ER-to-nucleus signal kinase 1 (IRE1), and $\mathrm{C} / \mathrm{EBP}$ homologous protein (CHOP), indicating activation of ER stress signaling (86). Furthermore, fluoride also induced testicular inflammation, as manifested by gene up-regulation of tumor necrosis factor- $\alpha$ (TNF- $\alpha)$, interleukin-1 $\beta$ (IL-1 $\beta$ ), inducible nitric oxide synthase (iNOS) and cyclooxygenase2 (COX-2), in a nuclear factor-kB (NF-kB)-dependent manner (86). These were associated with marked histopathological lesions including injury of spermatogonia, decrease of spermatocytes and absence of elongated spermatids, as well as severe ultrastructural abnormalities in testes, such as endoplasmic reticulum stress (86).

Testis of mice exposed to fluoride revealed 763 differentially expressed genes, including 330 up-regulated and 433 down-regulated genes, which were involved in spermatogenesis, apoptosis, DNA damage, DNA replication, cell differentiation, protease inhibitor activity, ubiquitin mediated proteolysis, and the signaling pathways of calcium, 


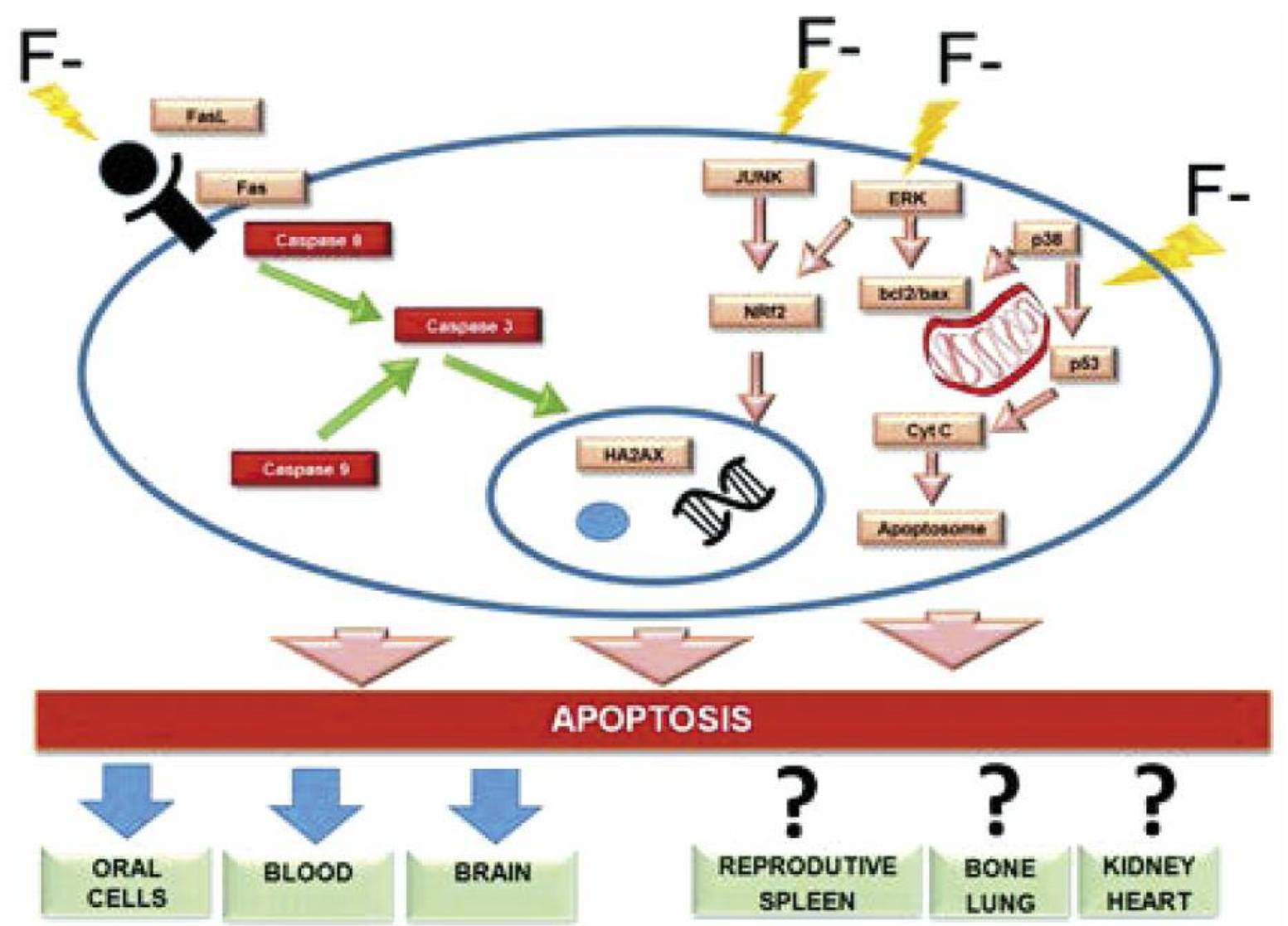

Figure 1. Pathobiological mechanisms of the apoptosis process induced by fluoride in mammalian cells.

JAK-STAT, MAPK, p53, Wnt, which were proved to be directly related to sperm quality $(87,88)$. Furthermore, more apoptotic spermatogenic cells were observed in the fluoride group, and the spermatogonium was markedly increased in $S$ phase and decreased in $G_{2} / M$ phase by fluoride (87). Taken as a whole, global genome microarray provides an insight into the reproductive toxicity induced by fluoride. However, additional molecular pathway analysis is needed (88).

Diffuse apoptosis in glandular epithelium and stromal cells were found in endometrial tissues of fluoride treated rats by the TUNEL method (89). Rats exposed to 100 or $200 \mathrm{mg} / \mathrm{L}$ $\mathrm{NaF}$ in their drinking water for 6 months showed ovarian apoptosis (90). Further investigations in ovarian granular cells showed that exposure to $\mathrm{NaF}$ activated extracellular regulated protein kinase (ERK) and c-Jun NH2 kinase (JNK), disrupting the ERK and JNK signaling pathways, while p38 and PI3K remained unchanged (90). Therefore, we assume that the majority of published papers are dedicated to the inflammatory host response induced by fluoride rather than apoptosis in vivo. Further studies are necessary to elucidate the issue.
Central nervous system. It has been established that fluoride is an important target when investigating the central nervous system because it induces oxidative stress, glial activation and inflammation which leads to neurodegeneration (91). All of those changes lead to abnormal cell differentiation and the activation of apoptosis through changes in the expression of neural cell adhesion molecules (NCAM), glial fibrillary acidic protein (GFAP), brain-derived neurotrophic factor (BDNF) and MAP kinases (91). Excessive exposure to this element can cause harmful effects such as permanent damage of all brain structures, impaired learning ability, memory dysfunction and behavioural problems (91).

Bcl-2 expression levels significantly decreased while caspase 12 levels were increased, in brain cells of rats offspring exposed to fluoride during gestation (87). Moreover, the number of apoptotic cells, the expression levels of cytochrome $c$ and the expression levels of caspase9 and caspase- 3 significantly increased (87). By contrast, caspase-9 and caspase- 3 protein levels significantly decreased in the rat brain exposed to fluoride (92). TUNEL assay revealed apoptosis of rat neurons with increasing 
fluoride concentrations (93). Bax protein expression increased and $\mathrm{Bcl}-2$ protein expression decreased in fluoridetreated rat brain compared with that of the control rat brain (93). The levels of IL-1 $\beta$ and IL-6 protein expression in microglial cells were significantly increased in the cortex and hippocampus of rats exposed to fluoride, and TNF- $\alpha$ immunoreactivity in microglial cells of the hippocampus was significantly higher in the $120 \mathrm{ppm}$ fluoride-treated group than that in the control group (93).

Kidney. Male Sprague-Dawley rats were treated with 0, 50, 100 , and $200 \mathrm{mg} / \mathrm{l}$ of $\mathrm{NaF}$, via drinking water for 120 days (94). The results showed that $\mathrm{NaF}$ treatment increased apoptosis and subsequent DNA damage (94). In addition, $\mathrm{NaF}$ treatment increased the protein expression levels of cytosolic Cyt $c$ and cleaved caspases 9, 8, and 3 (94). These results indicated that $\mathrm{NaF}$ induces apoptosis in rat kidneys through caspase-mediated intrinsic apoptosis pathway activation.

Avian broilers showed that the percentage of renal cell apoptosis was increased with increasing of dietary fluoride, when compared with that of the control group (95). Renal cells in $G_{0} / G_{1}$ phase were much higher, and renal cells in $S$ phase, $\mathrm{G}_{2}+\mathrm{M}$ phase, and proliferation index value were much lower in the high fluoride groups (95). Kidneys of rats exposed to fluoride showed the same results (96).

\section{Conclusion}

In this review, we present the published results regarding apoptosis induced by fluoride exposure in mammalian cells in vitro and in vivo (Figure 1). Some cell types such as oral cells, blood and brain were exetensively investigated; the results showed that fluoride is able to induce apoptosis in both intrinsinc and extrinsic pathways. Nevertheless, other cells types have been poorly investigated with conflicting results such as bone, kidney and reprodutive cells. Further studies using different endpoints, as well as to evaluate the role of cell cycle regulatory proteins, are important to understand the cytotoxicity as a result of apoptosis induced by fluoride. Such information is very important to elucidate what cell types are more sensitive to fluoride exposure. Therefore, this area needs further investigation for the safety of human populations exposed to fluoride in a chronic way, as for example in developing countries.

\section{References}

1 Chlubek D, Grucka-Mamczar E, Birkner E, Polaniak R, Stawiarska-Pieta B and Duliban H: Activity of pancreatic antioxidative enzymes and malondialdehyde concentrations in rats with hyperglycemia caused by fluoride intoxication. J Trace Element Med Biol 17: 57-60, 2003.
2 Everett ET: Fluoride's effects on the formation of teeth and bones, and the influence of genetics. J Dent Res 90(5): 552-560, 2011.

3 Aoba $\mathrm{T}$ and Fejerskov O: Dental fluorosis, chemistry and biology. Crit Rev Oral Biol Med 13(2): 155-170, 2002.

4 Shulman JD and Wells LM: Acute fluoride toxicity from ingesting home-use dental products in children, birth to 6 years of age. J Public Health Dent 57: 150-158, 1997.

5 Goodarzi F, Mahvi AH, Hosseini M, Nedjat S, Nabizadeh Nodehi R, Kharazifard MJ, Parvizishad M and Cheraghi Z: The prevalence of dental fluorosis and exposure to fluoride in drinking water, A systematic review. J Dent Res Dent Clin Dent Prospects 10(3): 127-135, 2016.

6 World Health Organization: Human health effects. In: Fluoride in drinking-water. Fawell J, Bailey K, Chilton J, Dahi E, Fewtrell L, Magara Y (eds.). London, IWA Publishing, pp. 2936, 2006.

7 Elmore S: Apoptosis: A Review of Programmed Cell Death Toxicol Pathol 35(4): 495-516, 2007.

8 Favaloro B, Allocati N, Grazino V, Di llio C and De Laurenzi V: Role of apoptosis in disease. Aging (Albany NY) 4(5): 330349, 2012.

9 Barbier O, Arreola-Mendoza L, Del Razo LM: Molecular mechanisms of fluoride toxicity. Chem Biol Interact 188(2): 319$333,2010$.

10 Jacinto-Alemán LF, Hernández-Guerrero JC, Trejo-Solís C, Jiménez-Farfán MD, Fernández-Presas AM: In vitro effect of sodium fluoride on antioxidative enzymes and apoptosis during murine odontogenesis. J Oral Pathol Med 39(9): 709-714, 2010.

11 Kanjevac T, Milovanovic M, Volarevic V, Lukic ML, Arsenijevic $\mathrm{N}$, Markovic D, Zdravkovic N, Tesic Z and Lukic A: Cytotoxic effects of glass ionomer cements on human dental pulp stem cells correlate with fluoride release. Med Chem 8(1): 40-45, 2012.

12 Wurtz T, Houari S, Mauro N, MacDougall M, Peters H and Berdal A: Fluoride at non-toxic dose affects odontoblast gene expression in vitro. Toxicology 249(1): 26-34, 2008.

13 Karube H, Nishitai G, Inageda K, Kurosu H and Matsuoka M: $\mathrm{NaF}$ activates MAPKs and induces apoptosis in odontoblast-like cells. J Dent Res 88(5): 461-465, 2009.

14 Li P, Xue Y, Zhang W, Teng F, Sun Y, Qu T, Chen X, Cheng X, Song B, Luo W and Yu Q: Sodium fluoride induces apoptosis in odontoblasts via a JNK-dependent mechanism. Toxicology 308: 138-145, 2013.

15 Yang T, Zhang Y, Zheng D, Hao Y, Snead ML and Duan X: Highfluoride promoted phagocytosis-induced apoptosis in a matured ameloblast-like cell line. Arch Oral Biol 60(1): 84-90, 2015.

16 Ribeiro DA, Hirota L, Cestari TM, Ceolin DS, Taga R and Assis GF: Ultrastructural morphometric analysis of ameloblasts exposed to fluoride during tooth development. J Mol Histol 37(8-9): 361-367, 2006.

17 Suzuki M and Bartlett JD: Sirtuin1 and autophagy protect cells from fluoride-induced cell stress. Biochim Biophys Acta 1842(2): 245-255, 2014.

18 Suzuki M, Bandoski C and Bartlett JD: Fluoride induces oxidative damage and SIRT1/autophagy through ROS-mediated JNK signaling. Free Radic Biol Med 89: 369-378, 2015.

19 Kubota K, Lee DH, Tsuchiya M, Young CS, Everett ET, MartinezMier EA, Snead ML, Nguyen L, Urano F and Bartlett JD: Fluoride induces endoplasmic reticulum stress in ameloblasts responsible for dental enamel formation. J Biol Chem 280(24): 23194-23202, 2005. 
20 Zhang Y, Zhang K, Ma L, Gu H, Li J and Lei S: Fluoride induced endoplasmic reticulum stress and calcium overload in ameloblasts. Arch Oral Biol 69: 95-101, 2016.

21 Zhao L, Li J, Su J, Snead ML and Ruan J: LS8 cell apoptosis induced by NaF through p-ERK and p-JNK-a mechanism study of dental fluorosis. Acta Odontol Scand 74(7): 539-549, 2016.

22 Yang T, Zhang Y, Li Y, Hao Y, Zhou M, Dong N and Duan X: High amounts of fluoride induce apoptosis/cell death in matured ameloblast-like LS8 cells by down-regulating Bcl-2. Arch Oral Biol 58(9): 1165-1173, 2013.

23 Yan Q, Zhang Y, Li W and Denbesten PK: Micromolar fluoride alters ameloblast lineage cells in vitro. J Dent Res 86(4): 336340, 2007.

$24 \mathrm{Li} \mathrm{W}$, Jiang B, Cao X, Xie Y and Huang T: Protective effect of lycopene on fluoride-induced ameloblasts apoptosis and dental fluorosis through oxidative stress-mediated Caspase pathways. Chem Biol Interact 261: 27-34, 2017.

25 Lei S, Zhang Y, Zhang K, Li J and Liu L: Effects of Fluoride on the Expression of Beclin 1 and mTOR in Ameloblasts. Cells Tissues Organs 200(6): 405-412, 2015.

26 Lee JH, Jung JY, Jeong YJ, Park JH, Yang KH, Choi NK, Kim SH and Kim WJ: Involvement of both mitochondrialand death receptor-dependent apoptotic pathways regulated by Bcl-2 family in sodium fluoride-induced apoptosis of the human gingival fibroblasts. Toxicology 243(3): 340-347, 2008.

27 Tabuchi Y, Yunoki T, Hoshi N, Suzuki N and Kondo T: Genes and gene networks involved in sodium fluoride-elicited cell death accompanying endoplasmic reticulum stress in oral epithelial cells. Int J Mol Sci 15(5): 8959-8978, 2014.

28 Chien $\mathrm{CH}$, Ali Chowdhury S, Sakagami H and Kanegae H: Enhancement of sodium fluoride-induced cell death by centrifugal force. In Vivo 20(1): 103-108, 2006.

29 Acra AM, Sakagami H, Matsuta T, Adachi K, Otsuki S, Nakajima H, Koh T, Machino M, Ogihara T, Watanabe K, Watanabe S, Salgado AV and Bastida NM: Effect of three fluoride compounds on the growth of oral normal and tumor cells. In Vivo 26(4): 657-664, 2012.

30 Otsuki S, Sugiyama K, Amano O, Yasui T and Sakagami H: Negative regulation of $\mathrm{NaF}-$ induced apoptosis by Bad-CAII complex. Toxicology 287(1-3): 131-136, 2011.

31 Wang Z, Yang X, Yang S, Ren G, Ferreri M, Su Y, Chen L and Han B: Sodium fluoride suppress proliferation and induce apoptosis through decreased insulin-like growth factor-I expression and oxidative stress in primary cultured mouse osteoblasts. Arch Toxicol 85(11): 1407-1417, 2011.

32 Yan X, Feng C, Chen Q, Li W, Wang H, Lv L, Smith GW and Wang J: Effects of sodium fluoride treatment in vitro on cell proliferation, apoptosis and caspase- 3 and caspase- 9 mRNA expression by neonatal rat osteoblasts. Arch Toxicol 83(5): 451458, 2009.

33 Yan X, Yan X, Morrison A, Han T, Chen Q, Li J and Wang J: Fluoride induces apoptosis and alters collagen I expression in rat osteoblasts. Toxicol Lett 200(3): 133-138, 2011.

34 Gu X, Han D, Chen W, Zhang L, Lin Q, Gao J, Fanning S and Han B: SIRT1-mediated FoxOs pathways protect against apoptosis by promoting autophagy in osteoblast-like MC3T3-E1 cells exposed to sodium fluoride. Oncotarget 7(40): 6521865230, 2016.
35 Inkielewicz-Stepniak I, Radomski MW and Wozniak M: Fisetin prevents fluoride- and dexamethasone-induced oxidative damage in osteoblast and hippocampal cells. Food Chem Toxicol 50(34): 583-589, 2012.

$36 \mathrm{Qu}$ WJ, Zhong DB, Wu PF, Wang JF and Han B: Sodium fluoride modulates caprine osteoblast proliferation and differentiation. J Bone Miner Metab 26(4): 328-334, 2008.

$37 \mathrm{Xu}$ S, Yang Y, Han S and Wu Z: ZIP1 and zinc inhibits fluorideinduced apoptosis in MC3T3-E1 cells. Biol Trace Elem Res 159(1-3): 399-409, 2014.

38 Wei M, Duan D, Liu Y, Wang Z and Li Z: Autophagy may protect MC3T3-E1 cells from fluoride-induced apoptosis. Mol Med Rep 9(6): 2309-2315, 2014.

39 Chien CH, Sakagami H, Kouhara M, Sasaki A, Matsumoto K and Kanegae $\mathrm{H}$ : Effect of simulated orthodontic forces on fluoride-induced cytotoxicity in MC3T3-E1 osteoblast-like cells. In Vivo 23(2): 259-265, 2009.

40 Matsuda SS, Silva TL, Buzalaf MA, Rodrigues AC and de Oliveira RC: Differential effects of fluoride during osteoblasts mineralization in $\mathrm{C} 57 \mathrm{BL} / 6 \mathrm{~J}$ and $\mathrm{C} 3 \mathrm{H} / \mathrm{HeJ}$ inbred strains of mice. Biol Trace Elem Res 161(1): 123-129, 2014.

41 Zhang YL, Luo Q, Deng Q, Li T, Li Y, Zhang ZL and Zhong JJ: Genes associated with sodium fluoride-induced human osteoblast apoptosis. Int J Clin Exp Med 8(8): 13171-1318, 2015.

$42 \mathrm{He} \mathrm{H}$, Wang H, Jiao Y, Ma C, Zhang H and Zhou Z: Effect of sodium fluoride on the proliferation and gene differential expression in human RPMI8226 Cells. Biol Trace Elem Res 167(1): 11-17, 2015.

43 Agalakova NI and Gusev GP: Transient activation of protein kinase $\mathrm{C}$ contributes to fluoride-induced apoptosis of rat erythrocytes. Toxicol In Vitro 2333(13): 265-268, 2013.

44 Salgado-Bustamante M, Ortiz-Pérez MD, Calderón-Aranda E, Estrada-Capetillo L, Niño-Moreno P, González-Amaro R and Portales-Pérez D: Pattern of expression of apoptosis and inflammatory genes in humans exposed to arsenic and/or fluoride. Sci Total Environ 408(4): 760-767, 2010.

45 Jothiramajayam M, Sinha S, Ghosh M, Nag A, Jana A and Mukherjee A: Sodium fluoride promotes apoptosis by generation of reactive oxygen species in human lymphocytes. J Toxicol Environ Health A 77(21): 1269-1280, 2014.

46 Deng H, Kuang P, Cui H, Chen L, Luo Q, Fang J, Zuo Z, Deng $J$, Wang $X$ and Zhao L: Sodium fluoride $(\mathrm{NaF})$ induces the splenic apoptosis via endoplasmic reticulum (ER) stress pathway in vivo and in vitro. Aging (Albany NY) 8(12): 3552-3567, 2016.

47 Deng H, Kuang P, Cui H, Chen L, Fang J, Zuo Z, Deng J, Wang X and Zhao L: Sodium fluoride induces apoptosis in cultured splenic lymphocytes from mice. Oncotarget 7(42): 67880-67900, 2016.

48 Song JS, Lee HY, Lee E, Hwang HJ and Kim JH: Cytotoxicity and apoptosis induction of sodium fluoride in human promyelocytic leukemia (HL-60) cells. Environ Toxicol Pharmacol 11(2): 85-91, 2002.

49 Ruppová K, Wsólová L, Sedlák J, Horváthová M and Urbancíková M: Detection of apoptotic changes in HeLa cells after treatment with paracetamol and sodium fluoride. Gen Physiol Biophys 18: 140-146, 1999.

50 Anuradha CD, Kanno S and Hirano S: Oxidative damage to mitochondria is a preliminary step to caspase-3 activation in fluoride-induced apoptosis in HL-60 cells. Free Radic Biol Med 31(3): 367-373, 2001. 
51 Otsuki S, Morshed SR, Chowdhury SA, Takayama F, Satoh T, Hashimoto K, Sugiyama K, Amano O, Yasui T, Yokote Y, Akahane K and Sakagami H: Possible link between glycolysis and apoptosis induced by sodium fluoride. J Dent Res $84(10)$ : 919-923, 2005.

52 Zhao W, Yang Y, Zhang YX, Zhou C, Li HM, Tang YL, Liang $\mathrm{XH}$, Chen $\mathrm{T}$ and Tang YJ: Fluoride-containing podophyllum derivatives exhibit antitumor activities through enhancing mitochondrial apoptosis pathway by increasing the expression of caspase-9 in HeLa cells. Sci Rep 5: 17175, 2015.

53 Liu YJ, Guan ZZ, Gao Q and Pei JJ: Increased level of apoptosis in rat brains and SH-SY5Y cells exposed to excessive fluoride-a mechanism connected with activating JNK phosphorylation. Toxicol Lett 204(2-3): 183-189, 2011.

54 Jiang C, Zhang S, Liu H, Guan Z, Zeng Q, Zhang C, Lei R, Xia T, Wang Z, Yang L, Chen Y, Wu X, Zhang X, Cui Y, Yu L and Wang A: Low glucose utilization and neurodegenerative changes caused by sodium fluoride exposure in rat's developmental brain. Neuromolecular Med 16(1): 94-105, 2014.

55 Zhang M, Wang A, He W, He P, Xu B, Xia T, Chen X and Yang $\mathrm{K}$ : Effects of fluoride on the expression of NCAM, oxidative stress, and apoptosis in primary cultured hippocampal neurons. Toxicology 236(3): 208-216, 2007.

56 Haojun Z, Yaoling W, Ke Z, Jin L and Junling W: Effects of NaF on the expression of intracellular $\mathrm{Ca} 2+$ fluxes and apoptosis and the antagonism of taurine in murine neuron. Toxicol Mech Methods 22(4): 305-308, 2012.

57 Xu B, Xu Z, Xia T, He P, Gao P, He W, Zhang M, Guo L, Niu $\mathrm{Q}$ and Wang A: Effects of the Fas/Fas-L pathway on fluorideinduced apoptosis in SH-SY5Y cells. Environ Toxicol 26(1): 8692, 2011.

58 Yang Y, Huang H, Ba Y, Cheng XM and Cui LX: Effect of oxidative stress on fluoride-induced apoptosis in primary cultured Sertoli cells of rats. Int J Environ Health Res 25(1): 19, 2015.

59 Yang Y, Lin X, Huang H, Feng D, Ba Y, Cheng X and Cui L: Sodium fluoride induces apoptosis through reactive oxygen species-mediated endoplasmic reticulum stress pathway in Sertoli cells. J Environ Sci (China) 30: 81-89, 2015.

60 Sun Z, Nie Q, Zhang L, Niu R, Wang J and Wang S: Fluoride reduced the immune privileged function of mouse Sertoli cells via the regulation of Fas/FasL system. Chemosphere 168: 318325, 2017.

61 Song Gh, Wang RL, Chen ZY, Zhang B, Wang HL, Liu ML, Gao JP and Yan XY: Toxic effects of sodium fluoride on cell proliferation and apoptosis of Leydig cells from young mice.J Physiol Biochem 70(3): 761-768, 2014.

62 Wang AG, Xia T, Chu QL, Zhang M, Liu F, Chen XM and Yang KD: Effects of fluoride on lipid peroxidation, DNA damage and apoptosis in human embryo hepatocytes. Biomed Environ Sci 17(2): 217-222, 2004.

63 Niu Q, Liu H, Guan Z, Zeng Q, Guo S, He P, Guo L, Gao P, Xu B, Xu Z, Xia T and Wang A: The effect of c-Fos demethylation on sodium fluoride-induced apoptosis in L-02 cells. Biol Trace Elem Res 149(1): 102-119, 2012.

64 Gutowska I, Baranowska-Bosiacka I, Baśkiewicz M, Milo B, Siennicka A, Marchlewicz M, Wiszniewska B, Machaliński B and Stachowska E: Fluoride as a pro-inflammatory factor and inhibitor of ATP bioavailability in differentiated human THP1 monocytic cells. Toxicol Lett 196(2): 74-79, 2010.
65 Thrane EV, Refsnes M, Thoresen GH, Låg M and Schwarze PE: Fluoride-induced apoptosis in epithelial lung cells involves activation of MAP kinases p38 and possibly JNK. Toxicol Sci 61(1): 83-91, 2001.

66 Ying J, Xu J, Shen L, Mao Z, Liang J, Lin S, Yu X, Pan R, Yan C, Li S, Bao Q and Li P: The effect of sodium fluoride on cell apoptosis and the mechanism of human lung BEAS-2B cells in vitro. Biol Trace Elem Res, 2017. doi: 10.1007/s12011-0170937-y. [Epub ahead of print]

67 Ameeramja J and Perumal E: Protocatechuic acid methyl ester ameliorates fluoride toxicity in A549 cells. Food Chem Toxicol, 2017. doi: 10.1016/j.fct.2016.12.024. [Epub ahead of print]

$68 \mathrm{He}$ LF and Chen JG: DNA damage, apoptosis and cell cycle changes induced by fluoride in rat oral mucosal cells and hepatocytes. World J Gastroenterol 12(7): 1144-1148, 2006.

69 Rao SM, Sherlin HJ, Anuja N, Pratibha R, Priya P and Chandrasekar T: Morphometry of buccal mucosal cells in fluorosis--a new paradigm. Hum Exp Toxicol 30(11): 1761-1768, 2011.

70 Tsai CL, Lin JW, Kuo HK, Tai MH, Wu YC, Shyr CR and Wu PC: Induction of apoptosis in rabbit oral mucosa by $1.23 \%$ acidulated phosphate fluoride gel. Arch Toxicol 82(2): 81-87, 2008.

71 Li J, Zhao L, Zhao X, Wang P, Liu Y and Ruan J: Foxo1 attenuates NaF-induced apoptosis of LS8 cells through the JNK and mitochondrial pathways. Biol Trace Elem Res, 2017. doi: 10.1007/s12011-017-1015-1. [Epub ahead of print]

72 Liu L, Zhang Y, Gu H, Zhang K and Ma L: Fluorosis induces endoplasmic reticulum stress and apoptosis in osteoblasts in vivo. Biol Trace Elem Res 164(1): 64-71, 2015.

73 Estrada-Capetillo BL, Ortiz-Pérez MD, Salgado-Bustamante M, Calderón-Aranda E, Rodríguez-Pinal CJ, Reynaga-Hernández E, Corral-Fernández NE, González-Amaro R and Portales-Pérez DP: Arsenic and fluoride co-exposure affects the expression of apoptotic and inflammatory genes and proteins in mononuclear cells from children. Mutat Res Genet Toxicol Environ Mutagen 761: 27-34, 2014.

74 Rocha-Amador DO, Calderón J, Carrizales L, Costilla-Salazar $\mathrm{R}$ and Pérez-Maldonado IN: Apoptosis of peripheral blood mononuclear cells in children exposed to arsenic and fluoride. Environ Toxicol Pharmacol 32(3): 399-405, 2011.

75 Luo Q, Cui H, Peng X, Fang J, Zuo Z, Deng J, Liu J and Deng Y: Dietary High Fluorine Alters Intestinal Microbiota in Broiler Chickens. Biol Trace Elem Res 173(2): 483-491, 2016.

76 Gutiérrez-Salinas J, Morales-González JA, Madrigal-Santillán E, Esquivel-Soto J, Esquivel-Chirino C, González-Rubio MG, Suástegui-Domínguez $\mathrm{S}$ and Valadez-Vega $\mathrm{C}$ : Exposure to sodium fluoride produces signs of apoptosis in rat leukocytes. Int J Mol Sci 11(9): 3610-3622, 2010.

77 Chouhan S and Flora SJ: Effects of fluoride on the tissue oxidative stress and apoptosis in rats: biochemical assays supported by IR spectroscopy data. Toxicology 254(1-2): 61-67, 2008.

78 Song GH, Huang FB, Gao JP, Liu ML, Pang WB, Li Wb, Yan $\mathrm{XY}$, Huo MJ and Yang X: Effects of fluoride on DNA damage and caspase-mediated apoptosis in the liver of rats. Biol Trace Elem Res 166(2): 173-182, 2015.

79 Zhan XA, Wang M, Xu ZR, Li WF and Li JX: Evaluation of caspase-dependent apoptosis during fluoride-induced liver lesion in pigs. Arch Toxicol 80(2): 74-80, 2006. 
80 Campos-Pereira FD, Lopes-Aguiar L, Renosto FL, Nogueira GA, Costa EF, Barbieri Pulz R, Silva-Zacarin EC, Oliveira CA, Pigoso AA and Severi-Aguiar GD: Genotoxic effect and rat hepatocyte death occurred after oxidative stress induction and antioxidant gene downregulation caused by long term fluoride exposureChem Biol Interact 264: 25-33, 2017.

81 Kanagaraj VV, Panneerselvam L, Govindarajan V, Ameeramja J and Perumal E: Caffeic acid, a phyto polyphenol mitigates fluoride induced hepatotoxicity in rats: A possible mechanism. Biofactors 41(2): 90-100, 2015.

82 Miao K, Zhang L, Yang S, Qian W and Zhang Z: Intervention of selenium on apoptosis and Fas/FasL expressions in the liver of fluoride-exposed rats. Environ Toxicol Pharmacol 36(3): 913920, 2013.

83 Chen T, Cui H, Cui Y, Bai C and Gong T: Decreased antioxidase activities and oxidative stress in the spleen of chickens fed on high-fluorine diets. Hum Exp Toxicol 30(9): 1282-1286, 2011.

84 Wang H, Zhou B, Niu R, Wang J, Zhang J and Wang J: Analysis of the roles of dietary protein and calcium in fluoride-induced changes in T-lymphocyte subsets in rat. Environ Toxicol 32(5): 1587-1595, 2017.

85 Zhang S, Niu Q, Gao H, Ma R, Lei R, Zhang C, Xia T, Li P, Xu C, Wang C, Chen J, Dong L, Zhao Q and Wang A: Excessive apoptosis and defective autophagy contribute to developmental testicular toxicity induced by fluoride. Environ Pollut 212: $97-$ 104, 2016.

86 Zhang S, Jiang C, Liu H, Guan Z, Zeng Q, Zhang C, Lei R, Xia T, Gao H, Yang L, Chen Y, Wu X, Zhang X, Cui Y, Yu L, Wang $\mathrm{Z}$ and Wang A: Fluoride-elicited developmental testicular toxicity in rats: roles of endoplasmic reticulum stress and inflammatory response. Toxicol Appl Pharmacol 271(2): 206-215, 2013.

87 Sun Y, Ke L, Zheng X, Li T, Ouyang W and Zhang Z: Effects of different levels of calcium intake on brain cell apoptosis in fluorosis rat offspring and its molecular mechanism. Biol Trace Elem Res 176(2): 355-366, 2017.

88 Su K, Sun Z, Niu R, Lei Y, Cheng J and Wang J: Cell cycle arrest and gene expression profiling of testis in mice exposed to fluoride. Environ Toxicol 32(5): 1558-1565, 2017.
89 Guney M, Oral B, Karahan N and Mungan T: Protective effect of caffeic acid phenethyl ester (CAPE) on fluoride-induced oxidative stress and apoptosis in rat endometrium. Environ Toxicol Pharmacol 24(2): 86-91, 2007.

90 Geng Y, Qiu Y, Liu X, Chen X, Ding Y, Liu S, Zhao Y, Gao R, Wang Y and He J: Sodium fluoride activates ERK and JNK via induction of oxidative stress to promote apoptosis and impairs ovarian function in rats. J Hazard Mater 272: 75-82, 2014.

91 Dec K, Łukomska A, Maciejewska D, Jakubczyk K, BaranowskaBosiacka I, Chlubek D, Wąsik A and Gutowska I: The influence of fluorine on the disturbances of homeostasis in the central nervous system. Biol Trace Elem Res 177(2): 224-234, 2017.

92 Zheng X, Sun Y, Ke L, Ouyang W and Zhang Z: Molecular mechanism of brain impairment caused by drinking-acquired fluorosis and selenium intervention. Environ Toxicol Pharmacol 43: 134-139, 2016.

93 Yan N, Liu Y, Liu S, Cao S, Wang F, Wang Z and Xi S: Fluoride-induced neuron apoptosis and expressions of inflammatory factors by activating microglia in rat Brain. Mol Neurobiol 53(7): 4449-4460, 2016.

94 Song GH, Gao JP, Wang CF, Chen CY, Yan XY, Guo M, Wang $\mathrm{Y}$ and Huang FB: Sodium fluoride induces apoptosis in the kidney of rats through caspase-mediated pathways and DNA damage. J Physiol Biochem 70(3): 857-868, 2014.

95 Bai C, Chen T, Cui Y, Gong T, Peng X and Cui HM: Effect of high fluorine on the cell cycle and apoptosis of renal cells in chickens. Biol Trace Elem Res 138(1-3): 173-180, 2010.

96 Yu RA, Xia T, Wang AG and Chen XM: Effects of selenium and zinc on renal oxidative stress and apoptosis induced by fluoride in rats. Biomed Environ Sci 19(6): 439-444, 2006.

Received June 19, 2017

Revised July 4, 2017

Accepted July 6, 2017 